\title{
New closed-loop insulin systems
}

\author{
Charlotte K. Boughton ${ }^{1}$ (D) Roman Hovorka ${ }^{1}$ (D)
}

Received: 30 September 2020 / Accepted: 28 October 2020 / Published online: 6 February 2021

(C) The Author(s) 2021, corrected publication 2021

\begin{abstract}
Advances in diabetes technologies have enabled the development of automated closed-loop insulin delivery systems. Several hybrid closed-loop systems have been commercialised, reflecting rapid transition of this evolving technology from research into clinical practice, where it is gradually transforming the management of type 1 diabetes in children and adults. In this review we consider the supporting evidence in terms of glucose control and quality of life for presently available closed-loop systems and those in development, including dual-hormone closed-loop systems. We also comment on alternative 'do-it-yourself' closedloop systems. We remark on issues associated with clinical adoption of these approaches, including training provision, and consider limitations of presently available closed-loop systems and areas for future enhancements to further improve outcomes and reduce the burden of diabetes management.
\end{abstract}

Keywords Artificial pancreas $\cdot$ Automated insulin delivery $\cdot$ Hybrid closed-loop $\cdot$ Review $\cdot$ Type 1 diabetes

$\begin{array}{ll}\text { Abbreviations } \\ \text { AHCL } & \text { Advanced hybrid closed-loop } \\ \text { App } & \text { Application (mobile phone) } \\ \text { CGM } & \text { Continuous glucose monitor } \\ \text { DIY } & \text { Do-it-yourself } \\ \text { MPC } & \text { Model predictive control } \\ \text { PID } & \text { Proportional integral derivative }\end{array}$

\section{Introduction and development of closed-loop systems}

Hybrid closed-loop insulin delivery systems are gradually transforming clinical management of type 1 diabetes. They comprise a subcutaneously worn continuous glucose monitor (CGM or glucose sensor) device, communicating with an algorithm that responds in real time to changes in sensor glucose levels, and adjusts the subcutaneous insulin infusion delivered by an insulin pump (Fig. 1).

Although the concept of glucose-responsive insulin delivery has been around for 50 years, earlier developments of closed-loop systems were hampered by the lack of accurate

Roman Hovorka rh347@cam.ac.uk

1 Wellcome Trust-Medical Research Council Institute of Metabolic Science, University of Cambridge, Cambridge, UK and reliable CGM systems, unavailability of wearable computational devices and secure wireless communication protocols, and challenged by limitations in insulin pump devices. With advances in CGM technology, the simplest form of automated insulin delivery was achieved with low-glucose suspend systems, where insulin delivery is suspended when the sensor glucose crosses a specified threshold, and predictive glucose management systems, where insulin delivery is suspended when an algorithm predicts that sensor glucose is likely to cross the low-glucose threshold [1,2]. These systems reduce hypoglycaemia, although sometimes at the expense of increased hyperglycaemia [3]. These were conceptually landmark steps in the journey towards fully automated insulin delivery and a true 'artificial pancreas' (Fig. 2).

A closed-loop system is a more sophisticated system, with a control algorithm adjusting insulin delivery (up and down) in response to real-time sensor glucose levels and other inputs, such as meal intake (Fig. 3). The algorithm can accommodate variability of insulin requirements between and within individual users, and account for limitations of CGM accuracy and imprecisions of subcutaneous insulin delivery. Adaptation of the control algorithm to changes in physiological conditions with real-time adjustment of closed-loop control parameters is beneficial for optimal performance. Several different types of control algorithm have been developed, including model predictive control (MPC) algorithms, proportional integral derivative (PID) controllers and fuzzy logic control approaches [4]. MPC algorithms calculate 


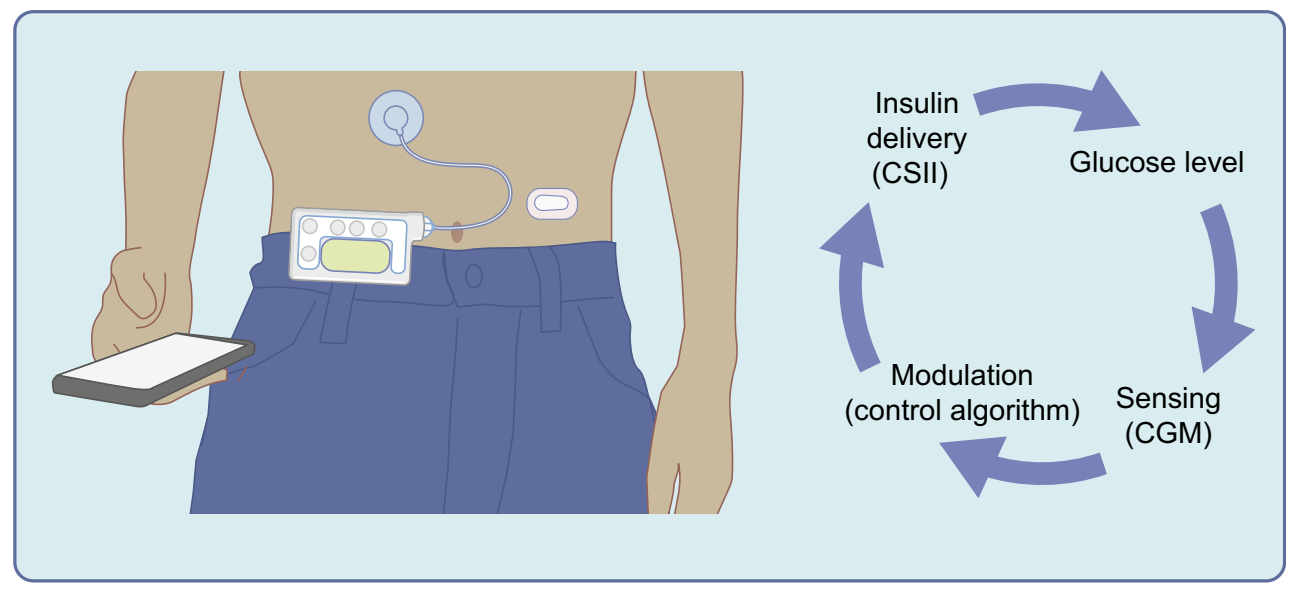

Fig. 1 Schematic of the configuration of closed-loop insulin delivery. A CGM transmits information about interstitial glucose concentrations to an algorithm hosted on a smartphone or insulin pump that translates information from the glucose sensor and computes the amount of insulin to deliver. An insulin pump delivers a rapid-acting insulin analogue

insulin delivery by minimising the difference between modelpredicted glucose concentrations and target glucose over a pre-specified prediction time horizon. PID controllers adjust insulin delivery by assessing glucose excursions from three perspectives: (1) deviation from target glucose (proportional component); (2) area under the curve between measured and target glucose (integral component); and (3) rate of change of measured glucose (derivative component). The fuzzy logic approach modulates insulin delivery based on approximate rules to express empirical knowledge of diabetes practitioners.

The first commercial closed-loop system, the MiniMed 670G (Medtronic, Northridge, CA, USA) was approved by the US Food and Drug Administration in September 2016 for use in people with type 1 diabetes aged 14 years and older [5]. This hybrid closed-loop system requires users to manually enter subcutaneously. Insulin delivery is modulated in real time by the control algorithm. Communication between system components is wireless. CSII, continuous subcutaneous insulin infusion. Figure adapted from [36]. This figure is available as part of a downloadable slideset

prandial insulin with automation of insulin delivery between meals and overnight. Several other hybrid closed-loop systems have since been commercialised and are increasingly being utilised in routine clinical care for people with type 1 diabetes.

\section{Efficacy and safety of hybrid closed-loop systems}

Clinical studies evaluating the safety and efficacy of hybrid closed-loop systems have evolved from small, highly supervised studies, undertaken overnight or over $24 \mathrm{~h}$ in research facilities, to larger randomised controlled trials of unrestricted home living use, conducted over 6 months or longer. A meta-analysis, published in 2018, of 40 early outpatient studies, reports the
Fig. 2 Key developmental milestones towards a truly artificial pancreas. This figure is available as part of a downloadable slideset

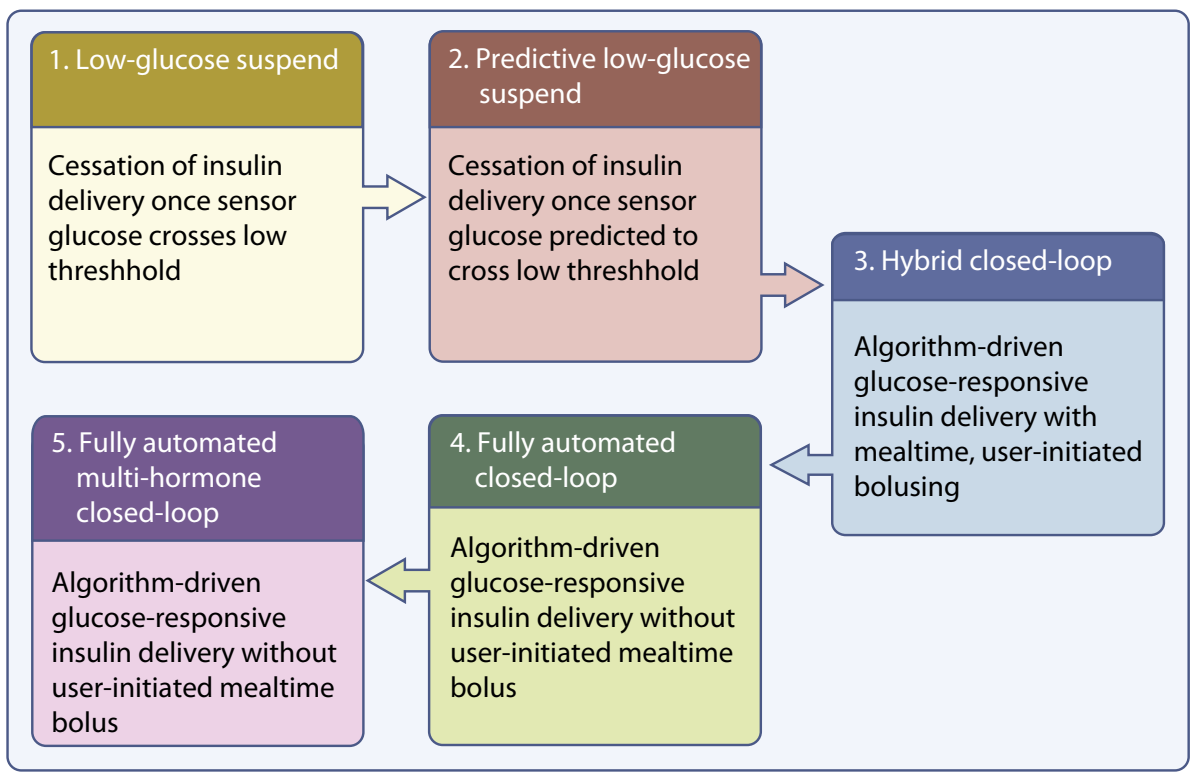


Fig. 3 Hybrid closed-loop glucose control. (a) $24 \mathrm{~h}$ of sensor glucose data. Green shaded area is the target glucose range (3.9$10 \mathrm{mmol} / \mathrm{l}$ ). Green triangles indicate carbohydrate (carbs) intake. (b) Algorithm-driven insulin delivery and manual insulin boluses. Data in both graphs derived from a Cambridge closed-loop study participant (the individual provided permission to share this anonymised data for the purpose of advancement of science). The graphs were generated using the data management platform Diasend (https://diasend.com//en). Image credit: Glooko Inc. All rights reserved. 2021. The $x$-axes show time in hours. This figure is available as part of a downloadable slideset a

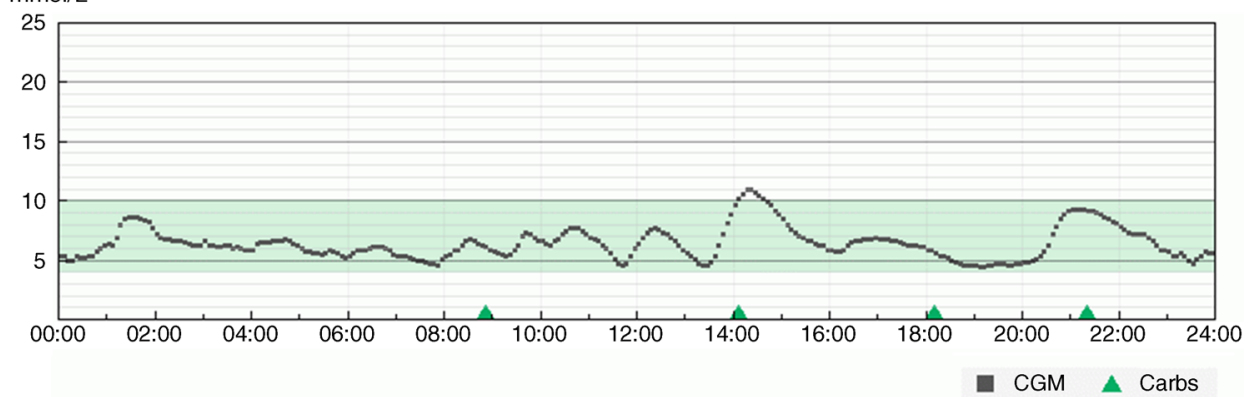

b

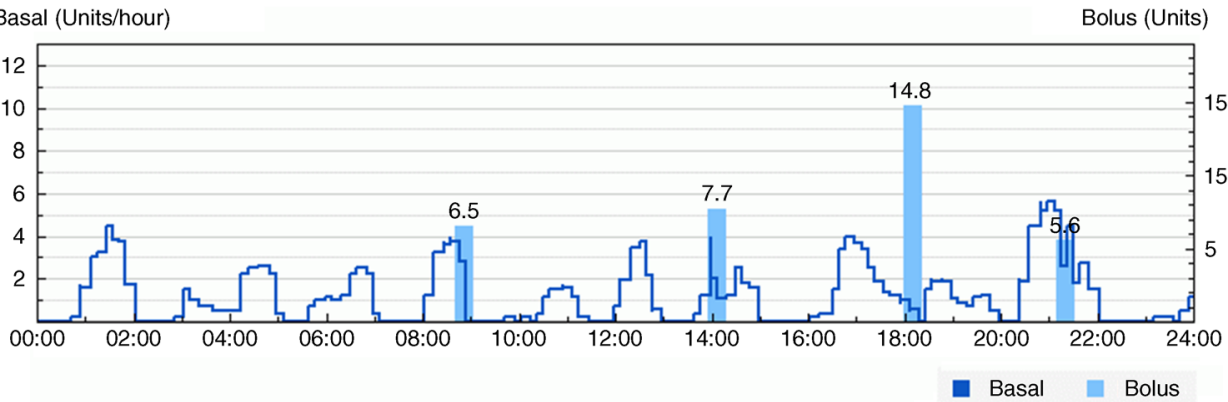

efficacy and safety of hybrid closed-loop systems in people with type 1 diabetes [6]. Earlier closed-loop systems were associated with a 9.6 percentage point improvement in time in target glucose range (3.9-10.0 mmol/l) compared with comparator therapies ( $>2$ additional $\mathrm{h} /$ day) and reduced time in hypoglycaemia ( $<3.9 \mathrm{mmol} / \mathrm{l}$ ) by 1.5 percentage points (approximately $20 \mathrm{~min} /$ day) compared with control treatment. Hybrid closed-loop systems have a favourable effect on $\mathrm{HbA}_{1 \mathrm{c}}$, with a reduction of $0.3-0.4 \%$ compared with control therapy in studies with a duration of more than 8 weeks per intervention. While this effect appears modest, this is despite the reduction in hypoglycaemia observed in several of these studies, as well as the low $\mathrm{HbA}_{1 \mathrm{c}}$ at recruitment, reflecting good baseline glycaemic control of study participants. Similar benefits have been reported in a metaanalysis of 25 studies in the paediatric population [7].

Individual randomised controlled trials demonstrate glycaemic benefits of hybrid closed-loop systems vs comparator therapies, but comparisons of efficacy between hybrid closed-loop systems across different studies is hampered by variation in baseline characteristics of participants, study duration and design. Studies including participants with variable experience in diabetes technology use (on multiple daily insulin injections and without previous sensor use) and from more diverse socioeconomic backgrounds are important to support generalisability of benefits.

\section{Psychosocial impact of closed-loop systems}

The impact of closed-loop technology on quality-of-life measures has been explored in several studies [8].
Psychosocial benefits reported by users include reduced anxiety, improved sleep and confidence from improved overnight glucose control, less restrictive eating habits and 'time off' from the demands of diabetes management. Reported challenges include technical issues, alarm intrusiveness and equipment burden, in addition to initial difficulties trusting the system. Most participants in closed-loop studies report that they would continue using closed-loop therapy or would recommend it to others as the clinical benefits outweigh system shortcomings. Psychosocial studies have largely included participants involved in closed-loop trials who may not be representative of the wider population living with type 1 diabetes.

\section{Commercially available closed-loop systems}

Details of the commercially available hybrid closed-loop systems can be found in Table 1 and an overview of key clinical studies are shown in Table 2.

Medtronic 670G and 780G Safety and efficacy of the first commercially approved hybrid closed-loop system (Medtronic 670G insulin pump with Guardian 3 sensor) was evaluated in a non-randomised before-and-after study in 30 adolescents and 94 adults with type 1 diabetes, over 3 months (Table 2) [9]. The proportion of time spent in target glucose range $(3.9-10 \mathrm{mmol} / \mathrm{l})$ increased from $60 \%$ at baseline to $67 \%$ with the closed-loop system in adolescents, and from $69 \%$ to $74 \%$ in adults. Time spent in hypoglycaemia $(<3.9 \mathrm{mmol} / \mathrm{l})$ was reduced with the closed-loop system and there were no 
Table 1 Commercially available hybrid closed-loop systems

\begin{tabular}{|c|c|c|c|c|}
\hline Component & Medtronic 670G & Medtronic 780G & CamAPS FX & Control-IQ \\
\hline Algorithm & PID with insulin feedback & PID with insulin feedback & $\begin{array}{l}\text { Treat to target adaptive } \\
\text { MPC } \\
\text { (Cambridge algorithm) }\end{array}$ & $\begin{array}{l}\text { Treat to range predictive } \\
\text { algorithm }\end{array}$ \\
\hline Insulin pump & $670 \mathrm{G}$ & $780 \mathrm{G}$ & Dana RS, Dana-i & Tandem t:slim X2 \\
\hline CGM system & $\begin{array}{l}\text { Guardian } 3 \\
\quad \text { (requires } \sim 4-6 \text { fingersticks/day) }\end{array}$ & $\begin{array}{l}\text { Guardian } 3 \\
\quad \text { (requires } \sim 4 \text { fingersticks/day) }\end{array}$ & $\begin{array}{l}\text { Dexcom G6 } \\
\text { (factory calibrated, } \\
\quad \text { optional calibration) }\end{array}$ & $\begin{array}{l}\text { Dexcom G6 } \\
\text { (factory calibrated, } \\
\quad \text { optional calibration) }\end{array}$ \\
\hline \multirow[t]{3}{*}{ Target glucose } & Fixed target: $6.7 \mathrm{mmol} / 1$ & $\begin{array}{l}\text { Target: } 5.6 \mathrm{mmol} / 1 \text { (default) or } \\
\quad 6.7 \mathrm{mmol} / 1\end{array}$ & \multirow{3}{*}{$\begin{array}{l}\text { Target: } 5.8 \mathrm{mmol} / 1 \\
\text { (default); } \\
\text { customisable between } \\
4.4 \mathrm{mmol} / 1 \text { and } \\
11 \mathrm{mmol} / 1 \\
\text { Optional activity target }\end{array}$} & $\begin{array}{l}\text { Fixed target range: } \\
6.2-8.9 \mathrm{mmol} / 1\end{array}$ \\
\hline & \multirow[t]{2}{*}{ Optional activity target } & \multirow[t]{2}{*}{ Optional activity target } & & Night mode: $6.2-6.7 \mathrm{mmol} / 1$ \\
\hline & & & & Optional activity target \\
\hline $\begin{array}{l}\text { Algorithm } \\
\text { learning }\end{array}$ & Based on TDD & Based on TDD & $\begin{array}{l}\text { Adapts to prandial and } \\
\text { diurnal patterns }\end{array}$ & None \\
\hline \multirow{2}{*}{$\begin{array}{l}\text { Compatible } \\
\text { downloading } \\
\text { software }\end{array}$} & \multirow{2}{*}{$\begin{array}{l}\text { Carelink; manual downloading } \\
\text { of pump required }\end{array}$} & \multirow{2}{*}{$\begin{array}{l}\text { Carelink; automated app } \\
\text { compatibility }\end{array}$} & \multirow{2}{*}{$\begin{array}{l}\text { Diasend; automated } \\
\text { download }\end{array}$} & Clarity: sensor data \\
\hline & & & & $\begin{array}{l}\text { Diasend/Glooko; manual } \\
\text { downloading of pump } \\
\text { required }\end{array}$ \\
\hline
\end{tabular}

TDD, total daily dose

episodes of severe hypoglycaemia or diabetic ketoacidosis in the study. A similar before-and-after study evaluating use of this device in 105 younger children aged 7-13 years reported increased time in target range and reduced time in hypoglycaemia with the closed-loop system (Table 2) [10].

A second-generation advanced hybrid closed-loop (AHCL [780G, Medtronic]) system has been developed to further improve glycaemic control and usability, with adjustable target glucose and automated correction boluses. The Fuzzy Logic Automated Insulin Regulation (FLAIR) study directly compared the Medtronic 670G with the AHCL system in adolescents and young adults with type 1 diabetes. Time in target glucose range was higher with the AHCL system than with the Medtronic 670G, while time in hypoglycaemia was similar (Table 2). The AHCL system was associated with fewer system alerts, reduced Auto Mode exits and increased time spent in Auto Mode (86\% vs 75\%) [11].

Tandem control-IQ In the longest randomised controlled closed-loop study to date, involving 168 people with type 1 diabetes (age $\geq 14$ years), the Control-IQ system (t:slim X2 pump with Dexcom G6 sensor [Tandem, San Diego, CA, USA]) was compared with sensor-augmented pump therapy over 6 months (Table 2; Fig. 4) [12]. Time in target glucose range increased by 10 percentage points from baseline with the closed-loop system (61\% to $71 \%)$ while there was no change in the control group (59\% to 59\%). Time spent in hypoglycaemia was reduced with the closed-loop system compared with the control group and there was an improvement in $\mathrm{HbA}_{1 \mathrm{c}}$. Notably, all participants completed the study, suggesting high acceptability of the technology.

In another study, the Control-IQ system was compared with sensor-augmented pump therapy in 101 younger children with type 1 diabetes, aged 6-13 years, over 16 weeks (Table 2). The closed-loop group had significantly greater improvements in time in target range, while the time spent in hypoglycaemia was similar between the closed-loop and control groups [13].

CamAPS FX CamAPS FX is the first interoperable hybrid closed-loop mobile phone application (app), utilising a control algorithm developed at the University of Cambridge (CamDiab; Cambridge, UK). At present, the app, hosted on an unlocked android smartphone, communicates with the Dana RS and Dana-i pumps and the Dexcom G6 sensor, but will communicate with additional pump and CGM systems in the future. The algorithm has been extensively evaluated in randomised controlled studies including children, adolescents, adults and pregnant women with type 1 diabetes $[14,15]$. In a randomised controlled trial including 86 children and adults with sub-optimal glycaemic control (baseline $\mathrm{HbA}_{1 \mathrm{c}}>$ $58 \mathrm{mmol} / \mathrm{mol}$ [7.5\%]), closed-loop use increased time in target range over 12 weeks compared with sensor-augmented pump therapy (Table 2) [16]. Time spent in hypoglycaemia was lower in the closed-loop group than the control group and $\mathrm{HbA}_{1 \mathrm{c}}$ also improved with closed-loop use.

Closed-loop insulin delivery using the Cambridge algorithm has been demonstrated to be feasible even in the very 
Table 2 Key clinical studies for commercially available hybrid closed-loop systems

\begin{tabular}{|c|c|c|c|c|c|}
\hline $\begin{array}{l}\text { Closed-loop device } \\
\text { [study reference] }\end{array}$ & Study design & $\begin{array}{l}\text { Study } \\
\text { duration }\end{array}$ & Population & Baseline $\mathrm{HbA}_{1 \mathrm{c}}$ & Glucose outcomes \\
\hline Medtronic 670G [9] & $\begin{array}{l}\text { Non-randomised } \\
\text { before-and-after } \\
\text { single-arm study }\end{array}$ & 3 months & $\begin{array}{l}n=30 \text { adolescents } \\
\quad \geq 14 \text { years old } \\
n=94 \text { adults }\end{array}$ & $\begin{array}{l}\text { Adolescents: } 7.7 \%(61 \\
\text { mmol } / \mathrm{mol}) ; \text { adults: } 7.3 \% \\
(56 \mathrm{mmol} / \mathrm{mol})\end{array}$ & $\begin{array}{l}\text { Adolescents: } \\
\text { - TIR } \uparrow \text { from } 60 \% \\
\text { (baseline) to } 67 \% \\
\text { - TBR } \downarrow \text { from } 4.3 \% \\
\text { (baseline) to } 2.8 \% \\
\text { Adults: } \\
\text { - TIR } \uparrow \text { from } 69 \% \\
\text { (baseline) to } 74 \% \\
\text { - TBR } \downarrow \text { from } 6.4 \% \\
\text { (baseline) to } 3.4 \%\end{array}$ \\
\hline Medtronic 670G [10] & $\begin{array}{l}\text { Non-randomised } \\
\text { before-and-after } \\
\text { single-arm study }\end{array}$ & 3 months & $\begin{array}{l}n=105 \text { children } \\
\quad(7-13 \text { years old })\end{array}$ & $7.9 \%(63 \mathrm{mmol} / \mathrm{mol})$ & $\begin{array}{l}\text { - } \mathrm{TIR} \uparrow \text { from } 56 \% \\
\text { (baseline) to } 65 \% \\
\text { - TBR } \downarrow \text { from } 4.7 \% \\
\text { (baseline) to } 3.0 \%\end{array}$ \\
\hline $\begin{array}{l}\text { Medtronic 780G } \\
\text { (AHCL) [11] }\end{array}$ & $\begin{array}{l}\text { Randomised crossover } \\
\text { study comparing Medtronic } \\
\text { AHCL with } 670 \mathrm{G}\end{array}$ & 3 months & $\begin{array}{c}n=113 \text { adolescents } \\
\text { and young adults } \\
(14-29 \text { years old })\end{array}$ & $7.9 \%(63 \mathrm{mmol} / \mathrm{mol})$ & $\begin{array}{l}\text { AHCL vs } 670 \mathrm{G}: \\
\text { - TIR } \uparrow: 67 \% \text { vs } 63 \% \\
\text { - TBR } \leftrightarrow: 2.1 \% \text { vs } 2.1 \%\end{array}$ \\
\hline Control-IQ [12] & $\begin{array}{l}\text { Randomised parallel study } \\
\text { comparing Control-IQ } \\
\text { with SAP }\end{array}$ & 6 months & $\begin{array}{l}n=168 \text { adults and } \\
\quad \text { adolescents } \\
\quad \geq 14 \text { years old }\end{array}$ & $7.4 \%(57 \mathrm{mmol} / \mathrm{mol})$ & $\begin{array}{l}\text { Control-IQ vs SAP: } \\
\text { - TIR } \uparrow: 71 \% \text { vs } 59 \% \\
\text { - TBR } \downarrow: 1.6 \% \text { vs } 2.3 \%\end{array}$ \\
\hline Control-IQ [13] & $\begin{array}{l}\text { Randomised parallel study } \\
\text { comparing Control-IQ } \\
\text { with SAP }\end{array}$ & 4 months & $\begin{array}{l}n=101 \text { children } \\
\quad(6-13 \text { years old })\end{array}$ & $\begin{array}{c}7.6-7.9 \%(60-63 \\
\mathrm{mmol} / \mathrm{mol})\end{array}$ & $\begin{array}{l}\text { Control-IQ vs SAP: } \\
\text { - TIR } \uparrow: 67 \% \text { vs } 55 \% \\
\text { - TBR } \leftrightarrow: 1.6 \% \text { vs } 1.8 \%\end{array}$ \\
\hline $\begin{array}{l}\text { Cambridge } \\
\text { closed-loop [16] }\end{array}$ & $\begin{array}{l}\text { Randomised parallel study } \\
\text { comparing closed loop } \\
\text { with SAP }\end{array}$ & 3 months & $\begin{array}{l}n=86 \text { children and } \\
\text { adults with } \\
\text { sub-optimal } \\
\text { glycaemic control }\end{array}$ & $\begin{array}{l}7.8-8.0 \% \\
\quad(62-64 \mathrm{mmol} / \mathrm{mol})\end{array}$ & $\begin{array}{l}\text { Closed loop vs SAP: } \\
\text { - TIR } \uparrow: 65 \% \text { vs } 54 \% \\
\text { - TBR } \downarrow: 2.6 \% \text { vs } 3.9 \%\end{array}$ \\
\hline $\begin{array}{l}\text { Cambridge } \\
\text { closed-loop [17] }\end{array}$ & $\begin{array}{l}\text { Randomised crossover } \\
\text { study comparing } \\
\text { closed-loop } \\
\text { using diluted insulin with } \\
\text { closed-loop using } \\
\text { standard-strength insulin }\end{array}$ & 3 weeks & $\begin{array}{l}n=24 \text { children } \\
\quad(2-7 \text { years old })\end{array}$ & $7.4 \%(57 \mathrm{mmol} / \mathrm{mol})$ & $\begin{array}{l}\text { For both groups: } \\
\text { - TIR: } 70-72 \% \\
\text { - TBR: } 4.5-4.7 \%\end{array}$ \\
\hline
\end{tabular}

SAP, sensor-augmented pump; TBR, time below range $(<3.9 \mathrm{mmol} / \mathrm{l})$; TIR, time in range $(3.9-10 \mathrm{mmol} / \mathrm{l})$

youngest of children, aged 1-7 years. In a study comparing the Cambridge closed-loop system using diluted insulin with the same closed-loop system using standard-strength insulin in children aged 2-7 years old, time in target glucose range was $>70 \%$ and time in hypoglycaemia was $<5 \%$ during both interventions. There were no safety or efficacy benefits of diluted insulin use compared with use of standard-strength insulin (Table 2) [17].

In a randomised controlled study involving 16 pregnant women with type 1 diabetes, closed-loop use overnight was associated with increased time in the tighter glucose range recommended during pregnancy $(3.5-7.8 \mathrm{mmol} / \mathrm{l})$ compared with sensor-augmented pump therapy (75\% vs $60 \%)$, without increasing the risk of hypoglycaemia [14]. During the continuation phase, the closed-loop system was used $24 \mathrm{~h} /$ day, including during labour and delivery, and time in target glucose range was $69 \%$.

\section{Anticipated commercial hybrid closed-loop systems}

The Diabeloop hybrid closed-loop system, comprising a handset containing the algorithm, Kaleido pump and Dexcom G6 sensor (DBLG1; Diabeloop, Grenoble, France), has been compared with sensor-augmented pump therapy in 68 adults with type 1 diabetes, in the home setting, with remote monitoring over 12 weeks [18]. Time with glucose in target range was 9 percentage points greater with closedloop therapy than with control therapy (69\% vs 59\%) and time 


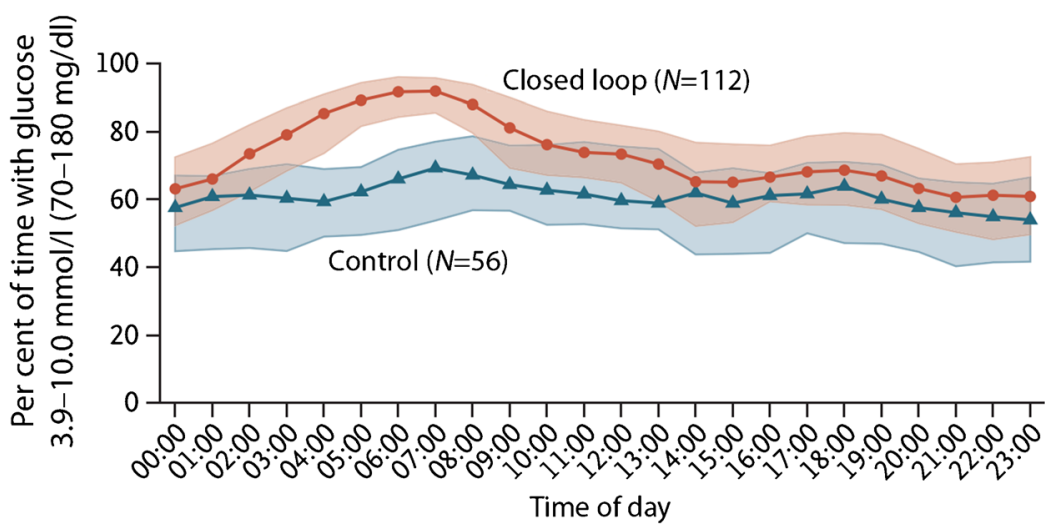

Fig. 4 Median percentage time with sensor glucose in target range during closed-loop insulin delivery (red line) and sensor-augmented pump therapy (blue line) in adults and adolescents $\geq 14$ years of age, using the Tandem Control-IQ closed-loop system [12]. The red and blue shaded

in hypoglycaemia was significantly lower with closed-loop use than during the control period. The DBLG1 hybrid closed-loop system has received the CE mark for use in adults with type 1 diabetes and is due to be commercialised.

The Insulet Omnipod Horizon hybrid closed-loop system, comprising the Omnipod pump and Dexcom G6 sensor (Insulet, Billerica, MA, USA), and Beta Bionics insulin-only iLet hybrid closed-loop system, comprising the iLet Bionic Pancreas System and Dexcom G6 sensor (Beta Bionics, Boston, MA, USA), are both currently being evaluated in pivotal trials with launches anticipated in the next $1-2$ years.

\section{Do-it-yourself closed-loop systems}

The do-it-yourself (DIY) artificial pancreas system (DIYAPS) communities arose out of their frustration with the slow progress of medical device development cycles (the \#wearenotwaiting movement). The communities develop and apply open-access closed-loop systems (e.g. the Open Artificial Pancreas System [OpenAPS], Loop and AndroidAPS), which do not undergo regulatory overview and approval. Without needing to await regulatory approval for new developments, these systems benefit from more rapid innovation cycles and can be more flexible in terms of customisation. In principle, access is open to anyone but users must be able to build and maintain their own system, albeit with support from the community itself. The role of healthcare providers in supporting the use of unregulated systems continues to be debated.

Several thousands of individuals use DIY systems globally. Observational before-and-after studies show improvements in time in target glucose range, $\mathrm{HbA}_{1 \mathrm{c}}$ and quality of life, but no longitudinal randomised controlled trials have evaluated the efficacy and safety of these systems [19]. A randomised clinical trial of a version of AndroidAPS is underway (ACTRN12620000034932p). areas indicate the interquartile range for each treatment. Figure adapted from [12]. Copyright: (02019 Massachusetts Medical Society. Reprinted with permission from Massachusetts Medical Society. This figure is available as part of a downloadable slideset

\section{Dual-hormone closed-loop systems}

The physiological glucagon response to hypoglycaemia is often impaired in type 1 diabetes; therefore, addition of glucagon to a closed-loop system confers additional protection from hypoglycaemia and may allow more aggressive insulin delivery to achieve improved glucose control. Potential benefits are countered by increased system complexity, requirement for two separate infusion systems and the lack of approved room-temperature-stable glucagon for chronic subcutaneous delivery. There are currently no commercially available dual-hormone closed-loop systems, although several are in development.

The longest dual-hormone closed-loop home study, with remote monitoring, included 43 adults with type 1 diabetes with optional meal announcements over a period of 11 days. Time in target glucose range was increased (78\% vs $62 \%)$ and hypoglycaemia $(<3.3 \mathrm{mmol} / \mathrm{l})$ was reduced $(0.6 \%$ vs $1.9 \%)$ with dual-hormone closed-loop use compared with insulin pump therapy alone [20]. A shorter study, over 5 days, involving 32 adolescents with type 1 diabetes, demonstrated a 21 percentage point increase in time in target glucose range during the closed-loop period compared with the control period, but time in hypoglycaemia was similar between groups [21]. An outpatient study of over $60 \mathrm{~h}$ compared dualhormone with single-hormone closed-loop systems in 23 adults with type 1 diabetes and showed no difference in time in target glucose range $(79 \%$ vs $75 \%)$ or time in hypoglycaemia ( $<4.0 \mathrm{mmol} / 1 ; 3.6 \%$ vs $3.9 \%)$, but longer studies are required to fully investigate potential differences [22].

Pramlintide is an analogue of amylin, which is co-secreted with insulin from beta cells and reduces postprandial glucose excursions by slowing gastric emptying [23]. A novel dualhormone closed-loop system delivering a fixed ratio of pramlintide:insulin was evaluated during a $24 \mathrm{~h}$ inpatient study in adults with type 1 diabetes. The dual-hormone system improved time in target range compared with an insulin-alone 
system ( $84 \%$ vs $74 \%$ ), an effect attributable to improved daytime glucose control [24]. Gastrointestinal symptoms were reported more frequently during use of closed-loop systems with pramlintide as compared with insulin only. Pramlintide co-delivery may support the development of fully closed-loop systems, obviating the need for manually initiated prandial insulin delivery.

\section{Training considerations}

High quality user and healthcare professional training is essential for ensuring that the clinical benefits of hybrid closed-loop systems are realised in the real-world setting. This is an important consideration for health economic analyses, to support adoption, implementation and reimbursement. Establishing realistic expectations of hybrid closed-loop therapy and reiterating the importance of core diabetes skills and tasks is important to promote long-term use and optimal clinical outcomes. Training programmes have been developed, using online and face-to-face approaches, to support users to maximise glycaemic and quality-of-life benefits of closedloop therapy [25].

\section{Limitations of closed-loop systems}

Early real-world use of the first commercially approved hybrid closed-loop system (Medtronic 670G) exposed issues around usability. The system required significant user input to remain in Auto Mode and, in one prospective observational study, one-third of users discontinued use of Auto Mode during the first year after initiation [26]. Factors influencing discontinuation include CGM issues (calibrations), number of alarms and efforts to limit Auto Mode exits [27]. Usability issues can prevent realisation of the benefits of closed-loop systems as increased time in Auto Mode is associated with improved glycaemic outcomes [28].

Some first-generation hybrid closed-loop systems use a relatively high glucose target $(6.7 \mathrm{mmol} / \mathrm{l})$ and lack flexibility to adjust the target to suit the needs of the user. This makes the system unsuitable for those aiming for tighter glycaemic control, including pregnant women.

Postprandial glucose excursions remain a challenge for closed-loop systems due to inherent delays in subcutaneous insulin absorption. User interaction with accurate carbohydrate counting and pre-meal bolusing is required for optimal glycaemic control. Attempts to reduce user burden with simplified meal boluses or fully closed-loop systems have resulted in compromised glycaemic control [29,30].

Managing physical activity can be challenging primarily due to increased hypoglycaemia risk and altered insulin sensitivity. Even with closed-loop glucose-responsive insulin delivery, users usually need to plan for exercise, announcing exercise to the algorithm in advance, and may still require carbohydrate intake to prevent hypoglycaemia [31, 32]. Carbohydrate loading before exercise can be problematic with glucose-responsive insulin delivery, often resulting in hypoglycaemia during exercise.

Important ethical considerations include ensuring equitable access, training and support for closed-loop technology, and protecting user confidentiality and safety from security breaches [33].

\section{Future developments in automated insulin delivery}

Future closed-loop systems will benefit from improved individual components; smaller, more accurate CGM devices with longer wear-time and smaller insulin pumps with the user interface transferred to a smartphone/watch will improve usability and minimise device burden. Interoperable devices and data management platforms offer flexibility for users to create their own personalised closed-loop ecosystem.

The introduction of new faster-acting insulin analogues (Fiasp and Ultra-Rapid Lispro) provides an opportunity to potentially improve performance of closed-loop systems with faster onset and offset of insulin action following subcutaneous delivery. Short studies comparing faster-acting insulin with standard insulin using the Medtronic 670G system have not shown significant benefits, but longer studies are required to fully evaluate closed-loop systems with faster-acting insulin $[34,35]$. Faster-acting insulins are not yet approved for use in the t:slim X2 pump and, hence, the Control-IQ closed-loop system.

Integration of additional signals to algorithms, such as heart rate or accelerometery, to more quickly detect physical activity than with CGM alone, may reduce exercise-related hypoglycaemia. If efficacious, this would be particularly beneficial in young children in whom activity is usually spontaneous and unpredictable and hypoglycaemia is a major concern.

\section{Conclusions}

The last 5 years has seen the successful transition of closedloop systems from research into routine clinical practice for management of type 1 diabetes. There is still scope for further improvements to optimise postprandial glucose control, exercise management and usability before this technology can be said to truly ameliorate the burden of diabetes. Widespread adoption and reimbursement of closed-loop systems will be critical to ensuring equitable access to this technology. 
Supplementary Information The online version contains a slideset of the figures for download available at https://doi.org/10.1007/s00125-02105391-w.

Funding Work in the authors group is supported by the National Institute of Health Research Cambridge Biomedical Research Centre, Efficacy and Mechanism Evaluation National Institute for Health Research, The Leona M. \& Harry B. Helmsley Charitable Trust, JDRF, National Institute of Diabetes and Digestive, and Kidney Diseases, Diabetes UK, Wellcome Trust Strategic Award (100574/Z/12/Z), and European Union Horizon 2020 research and innovation program (grant agreement no 731560).

Authors' relationships and activities RH reports having received speaker honoraria from Eli Lilly, Dexcom and Novo Nordisk, receiving license fees from B. Braun and Medtronic, and being director at CamDiab. CB declares that there are no relationships or activities that might bias, or be perceived to bias, their work.

Author's contribution Both authors were responsible for drafting the article and revising it critically for important intellectual content. Both authors approved the version to be published.

Open Access This article is licensed under a Creative Commons Attribution 4.0 International License, which permits use, sharing, adaptation, distribution and reproduction in any medium or format, as long as you give appropriate credit to the original author(s) and the source, provide a link to the Creative Commons licence, and indicate if changes were made. The images or other third party material in this article are included in the article's Creative Commons licence, unless indicated otherwise in a credit line to the material. If material is not included in the article's Creative Commons licence and your intended use is not permitted by statutory regulation or exceeds the permitted use, you will need to obtain permission directly from the copyright holder. To view a copy of this licence, visit http://creativecommons.org/licenses/by/4.0/.

\section{References}

1. Bergenstal RM, Klonoff DC, Garg SK et al (2013) Threshold-based insulin-pump interruption for reduction of hypoglycemia. N Engl J Med 369(3):224-232. https://doi.org/10.1056/NEJMoa1303576

2. Forlenza GP, Li Z, Buckingham BA et al (2018) Predictive lowglucose suspend reduces hypoglycemia in adults, adolescents, and children with type 1 diabetes in an at-home randomized crossover study: Results of the PROLOG trial. Diabetes Care 41(10):21552161. https://doi.org/10.2337/dc18-0771

3. Battelino T, Nimri R, Dovc K, Phillip M, Bratina N (2017) Prevention of hypoglycemia with predictive low glucose insulin suspension in children with type 1 diabetes: A randomized controlled trial. Diabetes Care 40(6):764-770. https://doi.org/10. 2337/dc16-2584

4. El Youssef J, Castle J, Ward WK (2009) A review of closed-loop algorithms for glycemic control in the treatment of type 1 diabetes. Algorithms 2(1):518-532. https://doi.org/10.3390/a2010518

5. Bergenstal R, Garg S, Weinzimer SA et al (2016) Safety of a hybrid closed-loop insulin delivery system in patients with type 1 diabetes. JAMA 316(13):1407-1408. https://doi.org/10.1001/jama.2016. 11708

6. Bekiari E, Kitsios K, Thabit $\mathrm{H}$ et al (2018) Artificial pancreas treatment for outpatients with type 1 diabetes: Systematic review and meta-analysis. BMJ 361. https://doi.org/10.1136/bmj.k1310
7. Karageorgiou V, Papaioannou TG, Bellos I et al (2019) Effectiveness of artificial pancreas in the non-adult population: A systematic review and network meta-analysis. Metabolism 90:20 30. https://doi.org/10.1016/j.metabol.2018.10.002

8. Farrington C (2018) Psychosocial impacts of hybrid closed-loop systems in the management of diabetes: A review. Diabet Med 35(4):436-449. https://doi.org/10.1111/dme.13567

9. Garg SK, Weinzimer SA, Tamborlane WV et al (2017) Glucose outcomes with the in-home use of a hybrid closed-loop insulin delivery system in adolescents and adults with type 1 diabetes. Diabetes Technol Ther 19(3):155-163. https://doi.org/10.1089/ dia.2016.0421

10. Forlenza GP, Pinhas-Hamiel O, Liljenquist DR et al (2019) Safety evaluation of the MiniMed 670G system in children 7-13 years of age with type 1 diabetes. Diabetes Technol Ther 21(1):11-19. https://doi.org/10.1089/dia.2018.0264

11. Bergenstal RM, Nimri R, Beck RW et al (2021) A comparison of two hybrid closed-loop systems in adolescents and young adults with type 1 diabetes (FLAIR): a multicentre, randomised, crossover trial. Lancet 397(10270):208-219. https://doi.org/10.1016/S01406736(20)32514-9

12. Brown SA, Kovatchev BP, Raghinaru D et al (2019) Six-month randomized, multicenter trial of closed-loop control in type 1 diabetes. N Engl J Med 381(18):1707-1717. https://doi.org/10.1056/ NEJMoa1907863

13. Breton MD, Kanapka LG, Beck RW et al (2020) A randomized trial of closed-loop control in children with type 1 diabetes. $\mathrm{N}$ Engl $\mathrm{J}$ Med 383(9):836-845. https://doi.org/10.1056/NEJMoa2004736

14. Stewart ZA, Wilinska ME, Hartnell S et al (2016) Closed-loop insulin delivery during pregnancy in women with type 1 diabetes. N Engl J Med 375(7):644-654. https://doi.org/10.1056/ NEJMoa1602494

15. Thabit H, Tauschmann M, Allen JM et al (2015) Home use of an artificial beta cell in type 1 diabetes. N Engl J Med 373(22):2129 2140. https://doi.org/10.1056/NEJMoa1509351

16. Tauschmann M, Thabit H, Bally L et al (2018) Closed-loop insulin delivery in suboptimally controlled type 1 diabetes: A multicentre, 12-week randomised trial. Lancet 392(10155):1321-1329. https:// doi.org/10.1016/S0140-6736(18)31947-0

17. Tauschmann M, Allen JM, Nagl K et al (2019) Home use of dayand-night hybrid closed-loop insulin delivery in very young children: A multicenter, 3-week, randomized trial. Diabetes Care 42(4): 594-600. https://doi.org/10.2337/dc18-1881

18. Benhamou PY, Franc S, Reznik Y et al (2019) Closed-loop insulin delivery in adults with type 1 diabetes in real-life conditions: A $12-$ week multicentre, open-label randomised controlled crossover trial. Lancet Digital Health 1(1):E17-E25

19. Lewis D, Leibrand S (2016) Real-world use of open source artificial pancreas systems. J Diabetes Sci Technol 10(6):1411. https://doi. org/10.1177/1932296816665635

20. El-Khatib FH, Balliro C, Hillard MA et al (2017) Home use of a bihormonal bionic pancreas versus insulin pump therapy in adults with type 1 diabetes: A multicentre randomised crossover trial. Lancet 389(10067):369-380. https://doi.org/10.1016/S01406736(16)32567-3

21. Russell SJ, El-Khatib FH, Sinha M et al (2014) Outpatient glycemic control with a bionic pancreas in type 1 diabetes. N Engl J Med 371(4):313-325. https://doi.org/10.1056/NEJMoa1314474

22. Haidar A, Messier V, Legault L, Ladouceur M, Rabasa-Lhoret R (2017) Outpatient 60-hour day-and-night glucose control with dualhormone artificial pancreas, single-hormone artificial pancreas, or sensor-augmented pump therapy in adults with type 1 diabetes: An open-label, randomised, crossover, controlled trial. Diabetes Obes Metab 19(5):713-720. https://doi.org/10.1111/dom.12880

23. Levetan C, Want LL, Weyer C et al (2003) Impact of pramlintide on glucose fluctuations and postprandial glucose, glucagon, and 
triglyceride excursions among patients with type 1 diabetes intensively treated with insulin pumps. Diabetes Care 26(1):1-8. https:// doi.org/10.2337/diacare.26.1.1

24. Haidar A, Tsoukas MA, Bernier-Twardy S et al (2020) A novel dual-hormone insulin-and-pramlintide artificial pancreas for type 1 diabetes: A randomized controlled crossover trial. Diabetes Care 43(3):597-606. https://doi.org/10.2337/dc19-1922

25. Berget C, Thomas SE, Messer LH et al (2020) A clinical training program for hybrid closed loop therapy in a pediatric diabetes clinic. J Diabetes Sci Technol 14(2):290-296. https://doi.org/10.1177/ 1932296819835183

26. Lal RA, Basina M, Maahs DM, Hood K, Buckingham B, Wilson DM (2019) One year clinical experience of the first commercial hybrid closed-loop system. Diabetes Care 42(12):2190-2196. https://doi.org/10.2337/dc19-0855

27. Messer LH, Berget C, Vigers T et al (2020) Real world hybrid closed-loop discontinuation: Predictors and perceptions of youth discontinuing the $670 \mathrm{G}$ system in the first 6 months. Pediatr Diabetes 21(2):319-327

28. Duffus SH, Ta'ani ZA, Slaughter JC, Niswender KD, Gregory JM (2020) Increased proportion of time in hybrid closed-loop "auto mode" is associated with improved glycaemic control for adolescent and young patients with adult type 1 diabetes using the MiniMed 670G insulin pump. Diabetes Obes Metab 22(4):688693. https://doi.org/10.1111/dom.13912

29. Weinzimer SA, Steil GM, Swan KL, Dziura J, Kurtz N, Tamborlane WV (2008) Fully automated closed-loop insulin delivery versus semiautomated hybrid control in pediatric patients with type 1 diabetes using an artificial pancreas. Diabetes Care 31(5): 934-939. https://doi.org/10.2337/dc07-1967

30. Gingras V, Rabasa-Lhoret R, Messier V, Ladouceur M, Legault L, Haidar A (2016) Efficacy of dual-hormone artificial pancreas to alleviate the carbohydrate-counting burden of type 1 diabetes: A randomized crossover trial. Diabetes Metab 42(1):47-54. https:// doi.org/10.1016/j.diabet.2015.05.001

31. Riddell MC, Zaharieva DP, Yavelberg L, Cinar A, Jamnik VK (2015) Exercise and the development of the artificial pancreas: One of the more difficult series of hurdles. J Diabetes Sci Technol 9(6):1217-1226. https://doi.org/10.1177/1932296815609370

32. Tagougui S, Taleb N, Legault L et al (2020) A single-blind, randomised, crossover study to reduce hypoglycaemia risk during postprandial exercise with closed-loop insulin delivery in adults with type 1 diabetes: Announced (with or without bolus reduction) vs unannounced exercise strategies. Diabetologia 63(11):22822291. https://doi.org/10.1007/s00125-020-05244-y

33. Quintal A, Messier V, Rabasa-Lhoret R, Racine E (2019) A critical review and analysis of ethical issues associated with the artificial pancreas. Diabetes Metab 45(1):1-10. https://doi.org/10.1016/j. diabet.2018.04.003

34. Hsu LJ, Buckingham BA, Basina M et al (2020) Fast-acting insulin aspart use with the MiniMed ${ }^{\mathrm{TM}}$ 670G system. Diabetes Technol Ther. https://doi.org/10.1089/dia.2020.0083

35. Bode BW, Carlson AL, Liu R et al (2020) 233-OR: Ultra-Rapid Lispro (URLi) demonstrates similar time-in-target range to Humalog with the Medtronic Minimed 670G hybrid closed-loop system. Diabetes 69(Supplement 1):233-OR (Abstract). https://doi. org $/ 10.1093 / \mathrm{jalm} / \mathrm{jfaa} 220$

36. Hovorka R (2011) Closed-loop insulin delivery: From bench to clinical practice. Nat Rev Endocrinol 7(7):385-395. https://doi. org/10.1038/nrendo.2011.32

Publisher's note Springer Nature remains neutral with regard to jurisdictional claims in published maps and institutional affiliations. 